\title{
Comparative Correlatives as Anaphora to Differentials
}

\author{
Adrian Brasoveanu \\ UC Santa Cruz
}

\section{Comparative and Equative Correlatives in Romanian}

The two goals of this paper are ( $i$ ) to establish that there are comparative correlatives that are not comparative conditionals and that the semantics of such correlatives crucially involves a relation (possibly the identity relation) between differentials (against much of the previous literature, e.g., McCawley 1988, Beck 1997) and (ii) to argue that a unified analysis should be given for such non-conditional, differential-based comparative (and equative) correlatives and the more familiar, conditional-like comparative correlatives.

Correlatives are "biclausal topic-comment structures [...] [in which] the dependent clause introduces one or more topical referents to be commented on by the matrix clause, where each topical referent must be picked up by - correlated with an anaphoric proform." (Bittner 2001). Differentials, e.g., $2 \mathrm{~cm}$ in the comparative Gabby is $2 \mathrm{~cm}$ taller than Linus, specify the difference between two measures, e.g., between Gabby's and Linus's heights.

\subsection{Non-Conditional Comparative and Equative Correlatives}

The first point is established by the existence of comparative correlatives with overt than-phrases (which are usually not acceptable in English) like the one in (1) below. Unless otherwise noted, all examples are in Romanian or English.

$\mathrm{Cu}$ cît e mai înalt fratele decît sora, (tot) cu With how much is more tall brother.the than sister.the, (also) with atît e mai înalt tatăl decît mama.

that much is more tall father.the than mother.the

'The brother is taller than the sister by a certain amount and the father is taller than the mother by the same amount.'

Intuitively, sentence (1) is true iff ( $i$ ) the brother is taller than the sister and the father is taller than the mother, that is, there is no conditionality (no if the brother is taller than the sister ...' kind of interpretation), and (ii) the difference in height between the brother and the sister is the same as the difference in height between

I am grateful to Daniel Altshuler, Pranav Anand, Rajesh Bhatt, Cleo Condoravdi, Sam Cumming, Donka Farkas, Simona Herdan, Slavica Kochovska, Sophia Malamud, Megan Moodie, Roumyana Pancheva, Asya Pereltsvaig, Octavian Popescu, Jessica Rett, Ivan Sag, Oana Săvescu, Roger Schwarzschild, two SALT XVIII reviewers and the $9^{\text {th }}$ Stanford Semantics Fest and SALT XVIII audiences for comments and / or data and / or judgments. The usual disclaimers apply. 
the father and the mother, that is, the correlative equates the two differentials under consideration (this is particularly clear if the particle tot is present).

These truth conditions are summarized by the formula in (2) below. Subscripts on terms indicate their type. The underlying logic is classical (many-sorted) type logic with three basic types: the usual $t$ (truth values - the domain $D_{t}$ of type $t$ consists of $\{\mathbb{T}, \mathbb{F}\}$ ) and $e$ (individuals - variables of type $e: x, x^{\prime}, y, y^{\prime}, \ldots$ ) plus the type of degrees $\gamma$ (from the Latin gradus - variables of type $\gamma: d, d^{\prime}, \ldots$ ). Differentials are intervals, i.e., convex sets of degrees of type $\gamma t$ (variables of type $\gamma t$ : $\left.D, D^{\prime}, \ldots\right)$. A formula of the form $\operatorname{tall}(x, d)$, where tall is a binary relation of type $\gamma($ et $)$, is interpreted as: the individual $x$ is at least $d$-tall (tall at least to degree $d$ ). I take definite descriptions to be anaphoric (for simplicity): the brother, the sister, the father and the mother retrieve the contextually specified values for the variables $x, x^{\prime}, y$ and $y^{\prime}$ respectively. Set-theoretic difference is symbolized as ' $\backslash$ '.

$$
\begin{aligned}
& \exists D_{\gamma t}\left(D \neq \emptyset \wedge D=\left\{d_{\gamma}: \operatorname{tall}(x, d)\right\} \backslash\left\{d^{\prime}{ }_{\gamma}: \operatorname{tall}\left(x^{\prime}, d^{\prime}\right)\right\} \wedge\right. \\
& \left.\exists D^{\prime}{ }_{\gamma t}\left(D^{\prime} \neq \emptyset \wedge D^{\prime}=\left\{d_{\gamma}: \operatorname{tall}(y, d)\right\} \backslash\left\{d^{\prime}{ }_{\gamma}: \operatorname{tall}\left(y^{\prime}, d^{\prime}\right)\right\} \wedge D=D^{\prime}\right)\right)
\end{aligned}
$$

The equative correlative in (3) below is non-conditional in the same way: on its most salient reading, sentence (3) is true iff ( $i$ ) Irina is (significantly) beautiful and (significantly) smart and (ii) the extent to which Irina is beautiful and the extent to which she is smart are (in some sense) equated / similar / comparable. ${ }^{1}$
Pe cît
e Irina de frumoasă, (tot) pe atît
e de deşteaptă.
PE how much is Irina DE beautiful, (also) PE that much is DE smart
'Irina is beautiful to a certain, significant extent and she is smart to the same, equally significant extent.'

\subsection{Conditional Comparative and Equative Correlatives}

The idea that non-conditional, differential-based comparative correlatives and the more familiar, conditional-like comparative correlatives should receive a unified analysis is supported by the correlatives in (4) and (5) below, which have the same basic syntax - except that the than-phrase is missing in (4) - and the same morphology - a wh-indefinite in the topic clause, a.k.a. apodosis, and an anaphoric demonstrative in the comment clause, a.k.a. protasis - as sentence (1) above.

$\mathrm{Cu}$ cît e un avocat mai agresiv, cu atît e mai eficient.

With how much is a lawyer more aggressive, with that much is more efficient 'The more aggressive a lawyer is, the more efficient s/he is.'

$\mathrm{Cu}$ cît e un număr natural mai mare decît altul, (\#tot) cu With how much is a number natural more great than another, (\#also) with atît e pătratul lui mai mare decît pătratul celuilalt. that much is square.the it.Gen more great than square.the other.one.Gen

\footnotetext{
${ }^{1}$ The first meaning component is not necessarily present in equative correlatives and it is systematically absent in certain cataphoric equative correlatives (where the apodosis precedes the protasis). For example, as a criterion for estimating the age of a tree, Un copac e pe atît de bătrîn pe cît e de gros (A tree is as old as it is thick) applies to all trees, including the very young and thin ones.
} 
'The greater one natural number is (than another), the greater its square is (than the square of the other one).'

Moreover, the interpretations of (4) and (5) are very closely related to the interpretation of (1). Intuitively, sentence (4) has two salient interpretations - it can be paraphrased by either the conditional in (6a) or the one in (6b) below, as Beck (1997) points out with respect to similar examples in German. These two interpretations are not necessarily two distinct readings, since (6b) is ultimately just a refinement of (6a) that examines the aggressiveness and efficiency of lawyers at various times as opposed to a single, contextually salient temporal interval.

a. If a lawyer $x$ is more aggressive than a lawyer $y$ by a certain amount, then $x$ is more efficient than $y$ by a corresponding amount.

b. If a lawyer $x$ is more aggressive at time $t$ than at time $t^{\prime}$ by a certain amount, then $x$ is more efficient at $t$ than at $t^{\prime}$ by a corresponding amount.

As $(6 a, b)$ above indicate, such conditional comparative correlatives involve a relation between differentials just as the non-conditional comparative correlative in (1) does. The truth conditions in (6a) are formalized in (7) below. The correspondence between the differential intervals $D$ and $D^{\prime}$ is implicitly contributed by the relative scope of the two quantifiers $\forall D\left(D \neq \emptyset \cdots \rightarrow \exists D^{\prime}\left(D^{\prime} \neq \emptyset \ldots\right)\right)$ : any non-empty aggressiveness interval $D$ induced by a pair of lawyers $x$ and $y$ is (somehow) related to a non-empty efficiency interval $D^{\prime}$ induced by the same pair of lawyers.

$$
\begin{aligned}
& \forall x_{e} \forall y_{e} \forall D\left(l w(x) \wedge l w(y) \wedge D \neq \emptyset \wedge D=\{d: \operatorname{aggr}(x, d)\} \backslash\left\{d^{\prime}: \operatorname{aggr}\left(y, d^{\prime}\right)\right\}\right. \\
& \left.\rightarrow \exists D^{\prime}\left(D^{\prime} \neq \emptyset \wedge D^{\prime}=\{d: \operatorname{eff}(x, d)\} \backslash\left\{d^{\prime}: \operatorname{eff}\left(y, d^{\prime}\right)\right\}\right)\right)
\end{aligned}
$$

The interpretation of sentence (5) when the particle tot is present provides the strongest argument in favor of differential-based truth conditions for conditional comparative correlatives: (5) with tot is true iff, for any two natural numbers $m$ and $n$ such that $m$ is greater than $n$, the difference $m-n$ is identical to the difference between their squares $m^{2}-n^{2}$, i.e., $\forall m_{e} \in \mathbb{N} \forall n_{e} \in \mathbb{N}\left(m>n \rightarrow m-n=m^{2}-n^{2}\right)$ (I take the set of natural numbers $\mathbb{N}$ to be a subset of the domain of individuals $D_{e}$ ). Thus, the relation between differentials implicitly contributed by $\forall D(D \neq \emptyset \cdots \rightarrow$ $\left.\exists D^{\prime}\left(D^{\prime} \neq \emptyset \ldots\right)\right)$ is now required to be the identity relation - which is why (5) with tot is intuitively false. And this falsity cannot be derived if the interpretation of (5) does not involve pairs of differential intervals that are required by tot to be identical. In contrast, (5) without tot is intuitively true because it just says that, for any natural numbers $m$ and $n$ such that $m>n$, their positive difference $m-n$ corresponds to a positive difference between their squares $m^{2}-n^{2}{ }^{2}$. The truth conditions of (5) are formalized in (8) below. The particle tot contributes the last conjunct $D=D^{\prime}$.

$$
\begin{aligned}
& \forall m_{e} \forall n_{e} \forall D\left(m \in \mathbb{N} \wedge n \in \mathbb{N} \wedge D \neq \emptyset \wedge D=\{d: \text { great }(m, d)\} \backslash\left\{d^{\prime}: \operatorname{great}\left(n, d^{\prime}\right)\right\}\right. \\
& \left.\rightarrow \exists D^{\prime}\left(D^{\prime} \neq \emptyset \wedge D^{\prime}=\left\{d: \operatorname{great}\left(m^{2}, d\right)\right\} \backslash\left\{d^{\prime}: \operatorname{great}\left(n^{2}, d^{\prime}\right)\right\} \wedge D=D^{\prime}\right)\right)
\end{aligned}
$$

\footnotetext{
${ }^{2}$ Note that, for a given $n$, the correspondence is an increasing function $f(m-n)=m^{2}-n^{2}$. In general, however, i.e., for varying $n$ and $m$, the correspondence between differentials is neither increasing nor functional: $(i)$ not increasing because, for example, $3-1>10-9$, but $3^{2}-1^{2}<$ $10^{2}-9^{2} ;$ (ii) not functional because, for example, $2-1=10-9$, but $2^{2}-1^{2} \neq 10^{2}-9^{2}$.
} 
The proposed truth conditions for conditional comparative correlatives are a refinement of the truth conditions in Beck (1997) (cf. p. 246:37"a, p. 252:51 and p. 253:52). The main difference is that the differential contributed by the protasis is available for anaphoric retrieval in the apodosis so that the protasis and apodosis differentials can be related (and, in certain cases, equated). We will see that this difference and the way in which the truth conditions are compositionally derived enable us to provide a unified analysis of both conditional and non-conditional comparative correlatives, with or without a than-phrase.

The proposed refinement of the truth conditions preserves an important result in Beck (1997), namely that comparative correlatives induce a correspondence between maximal degrees that is monotonically increasing and non-functional and, just like in Beck (1997), these two properties do not need to be separately stipulated, but follow automatically from the truth conditions.

Consider, for example, (4) above (and its English counterpart) under the reading in (6a). As noted in Beck (1997: 257 et seqq), an intuitively attractive paraphrase of (4) involves a monotonically increasing correspondence between the maximal degrees of aggressiveness and the maximal degrees of efficiency attributable to lawyers, which covary in a 'proportional' way. Formally (cf. Beck 1997: 258,(63b)):

$$
\begin{aligned}
& \exists F_{\gamma \gamma}\left(\operatorname{MON}^{\uparrow}(F) \wedge\right. \\
& \left.\forall x \forall d\left(l w(x) \wedge d=\operatorname{MAX}\left\{d^{\prime}: \operatorname{aggr}\left(x, d^{\prime}\right)\right\} \rightarrow F(d)=\operatorname{MAX}\left\{d^{\prime}: \operatorname{eff} f\left(x, d^{\prime}\right)\right\}\right)\right), \\
& \text { where } \operatorname{MON}^{\uparrow}(F) \text { is true iff } \forall d \forall d^{\prime}\left(d<d^{\prime} \rightarrow F(d)<F\left(d^{\prime}\right)\right) \\
& \text { and } \operatorname{MAX}\left\{d^{\prime}: \phi\left(d^{\prime}\right)\right\}:=\imath d . \phi(d) \wedge \forall d^{\prime}\left(\phi\left(d^{\prime}\right) \rightarrow d^{\prime} \leq d\right)^{3}
\end{aligned}
$$

Unlike Beck (1997) or the present proposal, this analysis does not involve pairs of lawyers. But, just like Beck (1997), it does not analyze comparative correlatives in terms of a relation between differentials: the correspondence $F$ in (9) between the protasis and the apodosis is formulated in terms of degrees. Hence, this analysis also fails to generalize to (conditional or non-conditional) comparative correlatives with overt than-phrases and comparative correlatives that require identity of differentials. But, independently of these issues, Beck (1997) puts forth two arguments against approaches formulated in terms of degree-based correspondences like the one in (9) above - and it is important to see that they do not apply to the present approach, formulated in terms of differential-based correspondences.

The first argument is that the correspondence $F$ has to be strictly monotonically increasing, otherwise we would incorrectly allow for functions $F$ that are not order preserving, e.g., functions mapping two distinct aggressiveness degrees $d<d^{\prime}$ to the same efficiency degree $F(d)=F\left(d^{\prime}\right)$ (lawyer $x$ is more aggressive than - but as efficient as - lawyer $y$ ) or two aggressiveness degrees $d<d^{\prime}$ to two

\footnotetext{
${ }^{3}$ The following variant of this formalization has been brought to my attention by Pranav Anand (p.c.): $\exists F_{\gamma \gamma}\left(\operatorname{MON}^{\uparrow}(F) \wedge \forall x \forall d\left(l w(x) \wedge \operatorname{MAX}\left\{d^{\prime}: \operatorname{aggr}\left(x, d^{\prime}\right)\right\}>d \rightarrow \operatorname{MAX}\left\{d^{\prime}:\right.\right.\right.$ eff $\left.\left(x, d^{\prime}\right)\right\}>$ $F(d))$ ). This version, which builds on the informal proposal in McCawley (1988), is preferable because of its closeness to the surface form of (4) (or its English counterpart). Moreover, as far as I can see, it is not subject to the 'functional' problem raised in Beck (1997: 257 et seqq). But this version also fails to generalize to comparative correlatives with overt than-phrases and comparative correlatives that require identity of differentials.
} 
inversely-ordered efficiency degrees $F\left(d^{\prime}\right)<F(d)$ (lawyer $x$ is more aggressive but less efficient - than lawyer $y$ ). The $\mathrm{MON}^{\uparrow}$ property needs to be separately stipulated in (9). In contrast, there is no need for such a stipulation in Beck's or the present analysis. The reason is the same in both cases: requiring every non-empty differential $D$ in the protasis to have a corresponding non-empty differential $D^{\prime}$ in the apodosis automatically ensures that every degree increase on the protasis scale is matched by a corresponding degree increase on the apodosis scale.

The second argument against approaches like (9) is that the correspondence between the two scales is not necessarily functional. Consider, for examples, the correlative (In last year's games) The warmer it got, the more goals Luise scored, based on Beck (1997: 261,72). This correlative is intuitively true in a situation in which two games took place while the temperature was $25^{\circ} \mathrm{C}$ and Luise scored 3 and 4 goals during those games - as long as she scored 2 goals when the temperature was $20^{\circ} \mathrm{C}$ and 5 goals when the temperature was $30^{\circ} \mathrm{C}$.

I take this argument to show that the degree-based correspondence intuitively established between the protasis and the apodosis is merely relational. Furthermore, this relation $R$ needs to be strictly monotonically increasing in the following sense: $\forall d \forall d^{\prime} \forall d^{\prime \prime} \forall d^{\prime \prime \prime}\left(d<d^{\prime} \wedge d R d^{\prime \prime} \wedge d^{\prime} R d^{\prime \prime \prime} \rightarrow d^{\prime \prime}<d^{\prime \prime \prime}\right)$. Now, the relation between differentials implicitly contributed by the formula $\forall D(D \neq \emptyset \cdots \rightarrow$ $\left.\exists D^{\prime}\left(D^{\prime} \neq \emptyset \ldots\right)\right)$ induces precisely this kind of monotonically increasing relation between degrees - and it induces it in a way that closely follows the overt morphosyntax of Romanian comparative correlatives like (1) and (5) above.

Further support for a unified analysis of conditional and non-conditional correlatives is provided by conditional equative correlatives like (10) below (interpreted roughly like (4)), which have the same morphology and syntax as nonconditional equative correlatives like (3) above.

Pe cît e de agresiv un avocat, pe atît e de eficient. $\mathrm{PE}$ how much is DE aggressive a lawyer, PE that much is DE efficient

'The aggressiveness of a lawyer is proportional to her/his efficiency.'

(11) \#Pe cît de mare e un număr, pe atît de mare e pătratul lui. \#PE how much DE great is a number, PE that much DE great is square.the it.Gen

'\#A number is equal to its square.'

As (11) above shows, the interpretation of such conditional equative correlatives is more constrained than the interpretation of their comparative correlative counterparts: (11) is not acceptable, in contrast to its counterpart without tot in (5) above, because it can only be interpreted as requiring the identity of two intervals. In this particular case, we falsely equate a number $m$ and its square $m^{2}$, for any number $m$.

\section{Comparative Correlatives as Anaphora to Differentials}

The main proposal is that the Romanian atît (that much) in (1), (3), (4), (5) and (10) above is anaphoric to differential intervals, i.e., at it is a proform in the degree 
domain, and the wh-differential cit (how much) is an indefinite introducing a nonempty interval, anaphorically retrieved by atît. ${ }^{4}$ The idea that atît is an intervalbased proform is supported by its anaphoric use in (12) below, which is similar to (1) above, and by its deictic use in (13) and its cataphoric use in (14) below.

(12) Fratele e mai înalt decît sora cu $2 \mathrm{~cm}$, iar tatăl e mai Brother.the is more tall than sister.the with $2 \mathrm{~cm}$, and father.the is more înalt decît mama tot $\mathrm{cu}$ atît. tall than mother.the also with that much

'The brother is $2 \mathrm{~cm}$ taller than the sister and the father is taller than the mother by the same amount.'

(13) E atît de obosită.

Is that much DE tired.f.sg

'She is so tired.'

(14) E atît de obosită încît o = doare capul.

Is that much DE tired.f.sg that her.Acc = hurts head.the

'She is so tired that she has a headache.'

The anaphora analysis enables us to capture the intuitive parallels between the interpretations of degree-based and individual-based correlatives. Consider, for example, the 'singular' / referential individual-based correlative in (15) below and the 'plural' / quantificational individual-based correlative in (16). Sentence (15) is parallel to (1) and (3): we refer to a single individual or a single pair of correlated intervals. Sentence (16) is parallel to (4), (5) and (10): we refer to a set of individuals or a set of pairs of correlated intervals. ${ }^{5}$

(15) Care fată şi = a = uitat ieri haina, pe aceea

Which girl her.Dat $=$ HAS $=$ forgotten yesterday coat.the, PE that one

o = caută tatăl ei.

her.Acc $=$ look for father.the her.Gen

'The father of the girl that forgot her coat yesterday is looking for her.'

(16) Pe care om $1=\mathrm{a}=$ interogat Securitatea, în acela nu PE which person him.Acc $=$ HAS $=$ interrogated security.the, in that one not mai am încredere.

anymore have.1sg trust

'I do not trust any person (whatsoever) that the secret police interrogated.'

Extending the investigation of anaphoric (and quantificational) parallels across domains initiated in Partee $(1973,1984)$ to encompass the degree domain is further supported by the following phenomena, exemplified in English:

\footnotetext{
${ }^{4}$ See Jespersen (1965) and den Dikken (2005) for related suggestions with respect to English comparative correlatives.

${ }^{5}$ See Dayal (1996), Bittner (2001) and Brasoveanu (2008) for more discussion of the semantics of individual-based correlatives.
} 
(17) Donkey anaphora:

a. Every child that ate a lot of vanilla ice cream yesterday ate twice as much chocolate ice cream today.

b. Every farmer who owns a donkey beats it.

(18) Quantificational subordination:

a. Harvey eats a lot of vanilla ice cream at every convention, but Linus always eats twice as much chocolate ice cream.

b. Harvey courts a woman at every convention. She always comes to the banquet with him. (Karttunen 1976)

(19) Modal subordination:

a. Harvey might bring a lot of vanilla ice cream to the party. In which case Linus would get competitive and bring twice as much chocolate ice cream.

b. A wolf might come in. It would eat you first. (Roberts 1989)

(20) Topicalization / Left Dislocation:

a. As smart as Linus is, Gabby is even smarter.

b. Megan, I like (her).

Thus, I take the non-conditional comparative correlative in (1) above to relate two cases,${ }^{6}$ one contributed by the protasis and the other by the apodosis. Each case features two heights and their differential and the two cases are related in terms of their respective differentials, which are equated. The conditional comparative correlatives in (4) and (5) are just a generalization of this basic pattern. They do not involve a single pair of cases related by means of their respective differentials, but involve multiple pairs of such cases. What is characterized in the literature (e.g., McCawley 1988, Beck 1997) as the conditionality of certain comparative correlatives is, under this analysis, just the fact that they correlate sets of cases.

The basic schema for the interpretation of comparative correlatives is provided in (21) below. The wh-morphology on the indefinite cît contributes a maximality operator max with scope over the rest of the protasis $\phi$. The max operator ensures that we take into consideration all cases, i.e., all sequences of objects, that satisfy the protasis. Each such case features a non-empty differential interval $D$, also contributed by the wh-indefinite - as indicated by the fact that $D$ is a superscript on cît. Then, the apodosis further elaborates on the set of cases contributed by the protasis: for each case / sequence, atît anaphorically retrieves the differential $D$ in that sequence - as indicated by the fact that $D$ is a subscript on atit - and relates it to a newly introduced differential $D^{\prime}$ that satisfies the rest of the apodosis $\psi$.

$$
\begin{array}{lll}
c u \quad c \hat{t}^{D}(\phi) & -c u \quad a t \hat{t i t}_{D} D^{\prime}(\psi) \rightsquigarrow \\
\max (D ; D \neq \emptyset ; \phi(D)) & - & D^{\prime} ; D^{\prime} \neq \emptyset ; \psi\left(D^{\prime}\right) ; \mathscr{R}\left(D, D^{\prime}\right)
\end{array}
$$

\footnotetext{
${ }^{6}$ I use 'case' in the sense of Lewis (1975); (minimal) situations would work as well.
} 
The value of the relational variable $\mathscr{R}$ is contextually specified. I assume that the Cartesian product $D_{\gamma t} \times D_{\gamma t}$ is always contextually salient and can therefore be the default value assigned to $\mathscr{R}$ - in which case we obtain the truth conditions in (7) above, where no particular constraints are placed on the relation between differentials. That is, if the value of $\mathscr{R}$ is $D_{\gamma t} \times D_{\gamma t}$, the requirement $\mathscr{R}\left(D, D^{\prime}\right)$ is vacuously satisfied, so we can drop it and obtain truth-conditions of the form $\forall D\left(D \neq \emptyset \cdots \rightarrow \exists D^{\prime}\left(D^{\prime} \neq \emptyset \ldots\right)\right)$.

The presuppositional particle tot (also) can require the relation $\mathscr{R}$ to be the identity relation between intervals - in which case we obtain the stronger truth conditions in (8) above, which have the form $\forall D\left(D \neq \emptyset \cdots \rightarrow \exists D^{\prime}\left(D^{\prime} \neq \emptyset \cdots \wedge D=\right.\right.$ $\left.D^{\prime}\right)$ ).

Finally, pragmatic factors can also force the value of $\mathscr{R}$ to be the identity relation, e.g., in (1) above. In this case, the requirement $D=D^{\prime}$ is present in the truth conditions whether the particle tot is present on not, as shown in (2) above.

The protasis and the apodosis of comparative correlatives are dynamically conjoined. This is a reflection of the fact that they are topic-comment structures: the protasis sets up a differential topic $D$ that the apodosis comments on. Dynamic conjunction ensures that the cases introduced in the protasis, including the $D$-differentials, are passed on to the apodosis.

The max operator always contributes the maximal set of cases satisfying the protasis and requires this set of cases to be non-empty. When the set of cases contributed by the protasis is a singleton set, like in (1) above, we have a nonconditional comparative correlative. Because we have a singleton set of cases, the truth conditions of such non-conditional comparative correlatives are basically existential and have the form $\exists D\left(D \neq \emptyset \cdots \wedge \exists D^{\prime}\left(D^{\prime} \neq \emptyset \cdots \wedge D=D^{\prime}\right)\right)$ - hence the formula in (2) above. When the set of cases contributed by the protasis is a nonsingleton set, like in (4) and (5) above, we have a conditional comparative correlative. Because the set of cases is not a singleton, the truth conditions of such conditional comparative correlatives are universal and have the form $\forall D(D \neq \emptyset \cdots \rightarrow$ $\left.\exists D^{\prime}\left(D^{\prime} \neq \emptyset \ldots\right)\right)$ - hence the formulas in (7) and (8) above.

Besides accounting for the variable conditionality of comparative correlatives, dynamically conjoining the protasis and the apodosis - in that order - enables us to capture the fact that we can have anaphora from the latter to the former, e.g., The more tyrannical $a^{x}$ man is, the less his son likes him, but not vice versa, e.g., The more reckless his $s_{x}$ son is, the less $a^{x}$ man likes him.

Given a suitable framework, both individual-based correlatives like (15) and (16) above and run-of-the-mill conditionals like If a wolf came in, it would / might eat you first (example based on Roberts 1989) can be analyzed along the same lines as (21) above. The only difference is that the protasis and the apodosis are correlated in terms of the individuals or possible scenarios / possible worlds that they characterize instead of differential intervals; see Brasoveanu (2008) for an analysis of individual-based correlatives and Brasoveanu (2007) (building on proposals in Stone (1999) and Bittner (2001)) for an analysis of conditionals along these lines.

Because modalized conditionals correlate cases by means of the possible scenarios / possible worlds that they evoke and that can never be exhaustively char- 
acterized up to singletonness (the set containing the actual world is the only modal singleton set that enters natural language interpretation - and it enters interpretation only deictically, never 'descriptively'), conditionality is always part of the meaning of modalized conditionals, but not of individual-based or degree-based correlatives.

\section{Anaphora to Differentials in Compositional Dynamic Semantics}

The formal analysis of comparative correlatives presents us with two problems: $(i)$ the variable conditionality problem and (ii) the compositionality problem that arises when there are no overt than-phrases, e.g., in (4) above.

We solve the conditionality problem by evaluating natural language expressions relative to - and letting them update - sets of sequences of objects (i.e., sets of cases in the sense of Lewis (1975)) instead of one sequence at a time.

We solve the compositionality problem by modeling such sequences of objects as stacks instead of total or partial variable assignments. ${ }^{7}$ The main motivation for using stacks is that we always add information to a stack (never overriding previous information) and we do this in an orderly manner, based on the particular position in the stack that the update targets. An important consequence for our analysis is that we can easily define a notion of stack 'splitting' (and re-concatenation), which enables us to 'generate' two independent variables out of the single indefinite un avocat (a lawyer) in (4) and compare their aggressiveness and efficiency.

Given the syntactically non-local, cross-clausal character of anaphora to differential intervals - which makes it similar to donkey anaphora -, the analysis is formalized in a dynamic semantics system. Following Muskens (1996), the system is couched in classical (many-sorted) type logic, which delivers Montague-style compositionality at sub-clausal level by the usual methods. In particular, we keep the three basic types introduced in section 1 above and add another basic type $s$ that models stacks / sequences of individuals (variables of type $s: i, j, \ldots$ ).

We indicate the empty positions in a stack $i$ by storing the dummy individual \# (type $e$ ) there, which is the universal falsifier (\# makes any lexical relation false).

$$
\text { A stack of length } n: \begin{array}{ccc|c|c|c|c|c|c|}
0 & 1 & \ldots & n-1 & n & n+1 & \ldots \\
\hline \alpha_{0} & \alpha_{1} & \ldots & \alpha_{n-1} & \# & \# & \ldots \\
\hline
\end{array}
$$

The length of a stack $i$, abbreviated $\operatorname{lng}(i)$, is the leftmost position in which $i$ stores an object different from the universal falsifier \# plus 1 , because the first position in a stack is the $0^{\text {th }}$ position. ${ }^{8}$ For example, the stack in (22) above is of length $n$. We abbreviate the empty stack (of length 0 ) as $i_{\emptyset}$ (that is, $i_{\emptyset}:=\imath j \cdot \operatorname{lng}(j)=0$ ). From now on, we will omit the cells storing the universal falsifier \# when we represent stacks.

\footnotetext{
${ }^{7}$ Following Bittner (2001), Nouwen (2003) and references therein.

${ }^{8}$ Stack length: $\operatorname{lng}(i)=1+\boldsymbol{l n} .(i)_{n} \neq \# \wedge \forall n^{\prime}>n\left((i)_{n^{\prime}}=\#\right)$ if $\exists n\left((i)_{n} \neq \# \wedge \forall n^{\prime}>n\left((i)_{n^{\prime}}=\#\right)\right)$; $\operatorname{lng}(i)=0$ if $\forall n\left((i)_{n}=\#\right)$; otherwise, $\operatorname{lng}(i)=\#$. The 'otherwise' case covers stacks of infinite length, for example, the stack storing the universal falsifier \# at all odd-number positions $1,3,5, \ldots$ and objects different from \# at the other positions.
} 
Stack update, defined in (24), never overrides previously introduced anaphoric information. When we update the $n^{\text {th }}$ position of a stack $i$, we obtain another stack $j$ by shifting all the $i$-objects stored at positions greater than or equal to $n$ by one position and introducing a new random object at position $n$. We can update a position $n$ only if no previous position stores the universal falsifier \#.

(23) Projection functions: $(i)_{n}$ is the object stored at position $n$ in stack $i$.

$$
i[n] j:=\forall m<n\left((j)_{m}=(i)_{m} \wedge(i)_{m} \neq \#\right) \wedge(j)_{n} \neq \# \wedge \forall m>n\left((j)_{m}=(i)_{m-1}\right)
$$

For simplicity, I will only use discourse referents (drefs) for individuals $u_{0}, u_{1}, \ldots$, which are functions of type $s e$, and drefs for intervals (sets of degrees) $\Delta_{0}, \Delta_{1}, \ldots$, which are functions of type $s(\gamma t)$. But we could just as easily add drefs for degrees $\delta_{0}, \delta_{1}, \ldots$ of type $s \gamma$ and, in general, drefs for objects of arbitrary static types, e.g., for binary relations between intervals $\mathscr{R}_{0}, \mathscr{R}_{1}, \ldots$ of type $s((\gamma t)((\gamma t) t))$. Drefs are type-driven projection functions over stacks. For example, $u_{n}:=\lambda i_{s} \cdot\left((i)_{e}\right)_{n}$ : for any stack $i$, the individual $u_{n}(i)-$ or $u i$ for short - is the $n^{\text {th }}$ individual, i.e., the $n^{\text {th }}$ object of type $e$ stored in $i$. Similarly, $\Delta_{n}:=\lambda i_{s} .\left((i)_{\gamma t}\right)_{n}$ : for any stack $i$, the interval $\Delta_{n}(i)$ - or $\Delta_{n} i$ for short - is the $n^{\text {th }}$ interval, i.e., the $n^{\text {th }}$ object of type $\gamma t$ stored in $i$. For any stack $i$ and any static type $\tau$ that we have drefs for (in our case, $\tau \in\{e, \gamma t\}$ ), the function $(i)_{\tau}$ retrieves the sub-stack of $i$ that stores the objects of type $\tau{ }^{9}$ '

We define the introduction of new drefs for individuals and intervals as shown in (25) below. All stacks $i$ consist of the individual sub-stack $(i)_{e}$ and the interval sub-stack $(i)_{\gamma t}$. When we update a stack $i$ with a dref $u_{n}$, we introduce a new random individual at the $n^{\text {th }}$ position of $(i)_{e}$, while $(i)_{\gamma t}$ remains unchanged. When we update a stack $i$ with a dref $\Delta_{n}$, we introduce a new random interval at the $n^{\text {th }}$ position of $(i)_{\gamma t}$, while $(i)_{e}$ remains unchanged.

$$
i\left[u_{n}\right] j:=(i)_{e}[n](j)_{e} \wedge(i)_{\gamma t}=(j)_{\gamma t} \text { and } i\left[\Delta_{n}\right] j:=(i)_{\gamma t}[n](j)_{\gamma t} \wedge(i)_{e}=(j)_{e}
$$

A set of five axioms ensures that the entities of type $s$ actually behave as stacks. ${ }^{10}$

To solve the variable conditionality problem, we work with plural information states $I, J, \ldots$, which are sets of stacks, i.e., terms of type st (van den Berg (1996) was the first to propose that natural language expressions should be evaluated relative to - and should dynamically update - sets of sequences of objects). Plural info states can be represented as matrices with stacks / sequences as rows:

\footnotetext{
${ }^{9}$ The initial position of type $\tau$ : ini $\mathbf{i}_{\tau}(i)=\imath n .(i)_{n} \in D_{\tau} \wedge(i)_{n} \neq \# \wedge \neg \exists n^{\prime}<n\left((i)_{n^{\prime}} \in D_{\tau} \wedge(i)_{n^{\prime}} \neq \#\right)$ if $\exists n\left((i)_{n} \in D_{\tau} \wedge(i)_{n} \neq \#\right)$; otherwise, $\mathbf{i n i}_{\tau}(i)=\#$. The final position of type $\tau$ : $\mathbf{f i n}_{\tau}(i)=\ln .(i)_{n} \in$ $D_{\tau} \wedge(i)_{n} \neq \# \wedge \neg \exists n^{\prime}>n\left((i)_{n^{\prime}} \in D_{\tau} \wedge(i)_{n^{\prime}} \neq \#\right)$ if $\exists n\left((i)_{n} \in D_{\tau} \wedge(i)_{n} \neq \#\right)$; otherwise, fin $_{\tau}(i)=\#$. The sub-stack of type $\tau$ : $(i)_{\tau}=i_{\emptyset}$ if $\mathbf{i n i}_{\tau}(i)=\mathbf{f i n}_{\tau}(i)=\#$; otherwise, $(i)_{\tau}=\imath j \cdot \operatorname{lng}(j)=1+\left(\mathbf{f i n}_{\tau}(i)-\right.$ $\left.\operatorname{ini}_{\tau}(i)\right) \wedge \forall n<\operatorname{lng}(j)\left((j)_{n}=(i)_{n+\mathbf{i n i}_{\tau}(i)}\right)$.

${ }^{10} \mathbf{A x 1}$ (stack identity in terms of projection functions) $-\forall i_{s} \forall i^{\prime}{ }_{s}\left(\forall n\left((i)_{n}=\left(i^{\prime}\right)_{n}\right) \rightarrow i=i^{\prime}\right)$; $\mathbf{A x 2}$ (stacks have finite length) $-\forall i_{s}(\exists n(\operatorname{lng}(i)=n)) ; \mathbf{A x 3}$ (the empty stack exists) $-\exists i_{s}(\operatorname{lng}(i)=0) ; \mathbf{A x 4}$ (only drefs for individuals and intervals; individuals before intervals and not interspersed with \#) $\forall i_{s} \forall n\left((i)_{n} \in D_{e} \vee(i)_{n} \in D_{\gamma t}\right) \wedge \forall i_{s} \forall n \forall n^{\prime}\left((i)_{n} \in D_{e} \backslash\{\#\} \wedge(i)_{n^{\prime}} \in D_{\gamma t} \rightarrow n<n^{\prime}\right) \wedge \forall i_{s} \forall n \forall n^{\prime}\left((i)_{n} \neq\right.$ $\left.\# \wedge(i)_{n^{\prime}} \neq \# \rightarrow \forall m\left(n<m<n^{\prime} \rightarrow(i)_{m} \neq \#\right)\right)$; Ax5 (enough stacks) $-\forall i_{s} \forall n \forall x_{e}\left(n \leq \operatorname{lng}\left((i)_{e}\right) \rightarrow\right.$ $\left.\exists j_{s}\left(i\left[u_{n}\right] j \wedge u_{n} j=x\right)\right) \wedge \forall i_{s} \forall n \forall D_{\gamma t}\left(n \leq \operatorname{lng}\left((i)_{\gamma t}\right) \rightarrow \exists j_{s}\left(i\left[\Delta_{n}\right] j \wedge \Delta_{n} j=D\right)\right)$.
} 


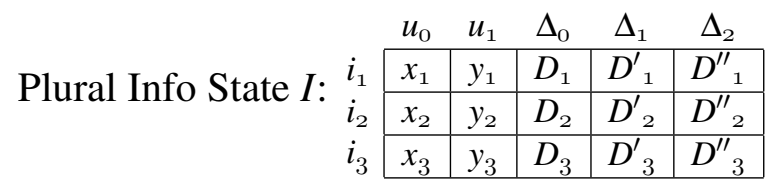

Such matrices are two-dimensional and enable us to encode two kinds of information: values and structure. Values are the sets of objects stored in the columns of the matrix, e.g., the dref $u_{0}$ stores a set of individuals $\left\{x_{1}, x_{2}, x_{3}\right\}$ relative to the plural info state $I$ in (26) above because $u_{0}$ is assigned an individual by each stack / row in $I$. Structure, that is, dependencies / relations between sets of values, is encoded in the rows of the matrix: for each stack / row in $I$, the individual assigned to $u_{0}$ by that stack is correlated with the individual assigned to $u_{1}$ by the same stack (and, also, with the intervals assigned to $\Delta_{0}, \Delta_{1}$ and $\Delta_{2}$ ). Structure is what enables us to analyze comparative correlatives (and correlatives in general) as introducing sets of cases and simultaneously elaborating on each of them.

A sentence is interpreted as a Discourse Representation Structure (DRS), i.e. as a relation of type $(s t)((s t) t)$ between an input state $I_{s t}$ and an output state $J_{s t}$. DRSs $\mathbb{D}, \mathbb{D}^{\prime}, \ldots$ are pairs of the form [new drefs|conditions] and they relate an input state $I$ and an output state $J$ iff $J$ differs from $I$ at most with respect to the new drefs and $J$ satisfies all the conditions. For example, $\left[u_{0}, \Delta_{0} \mid l w\left\{u_{0}\right\}\right.$, tall $\left.\left\{u_{0}, \Delta_{0}\right\}\right]:=$ $\lambda I_{s t} \cdot \lambda J_{s t} . I\left[u_{0}, \Delta_{0}\right] J \wedge l w\left\{u_{0}\right\} J \wedge$ tall $\left\{u_{0}, \Delta_{0}\right\} J-$ that is, $J$ differs from $I$ at most with respect to the individuals assigned to $u_{0}$ and the intervals assigned to $\Delta_{0}$ and all the $u_{0}$-individuals stored in $J$ are lawyers and they are $\Delta_{0}$-tall.

\section{$[$ new drefs $\mid$ conditions $]:=\lambda I_{s t} . \lambda J_{s t} . I[$ new drefs $] J \wedge$ conditions $J$}

Tests are DRSs that do not introduce new drefs: [conditions] $:=\lambda I_{s t} \cdot \lambda J_{s t} . I=$ $J \wedge$ conditions $J$. For example, $\left[\operatorname{tall}\left\{u_{0}, \Delta_{0}\right\}\right]:=\lambda I_{s t} . \lambda J_{s t} . I=J \wedge \operatorname{tall}\left\{u_{0}, \Delta_{0}\right\} J$.

Conditions are sets of info states (sets of sets of stacks), i.e., they are terms of type $(s t) t$. Moreover, conditions encoding lexical relations are distributive relative to the plural info states they accept: as shown in (28), (29) and (30) below, they accept an info state $I$ iff they accept each stack $i \in I$. The first conjunct $I \neq \emptyset$ rules out the case in which the second conjunct $\forall i_{s} \in I(\ldots)$ is vacuously satisfied.

$$
\begin{aligned}
& l w\left\{u_{n}\right\}:=\lambda I_{s t} . I \neq \emptyset \wedge \forall i_{s} \in I\left(l w\left(u_{n} i\right)\right) \\
& \text { eat }\left\{u_{m}, u_{n}\right\}:=\lambda I_{s t} . I \neq \emptyset \wedge \forall i_{s} \in I\left(\text { eat }\left(u_{m} i, u_{n} i\right)\right) \\
& \text { tall }\left\{u_{m}, \Delta_{n}\right\}:=\lambda I_{s t} . I \neq \emptyset \wedge \forall i_{s} \in I\left(\Delta_{n} i=\left\{d_{\gamma}: \operatorname{tall}\left(u_{m} i, d\right)\right\}\right)
\end{aligned}
$$

In the spirit of the Montagovian brace convention, the curly braces indicate that the static non-logical constants $l w$ (type et), eat (type $e(e t)$ ) and tall (type $\gamma(e t)$ ) apply to their dref arguments only after an index of evaluation (i.e., a stack $i$ ) is supplied.

A form of maximization over degrees is built into conditions like tall $\left\{u_{m}, \Delta_{n}\right\}$ : for each stack $i$, the interval $\Delta_{n} i$ contains all the degrees $d$ such that the individual $u_{m} i$ is at least $d$-tall. This will enable us to follow Beck (1997) and interpret the comparative morphology as (basically) relating two definite descriptions over degrees (see 43 below). I have chosen this formalization for simplicity and to facilitate 
the comparison with Beck (1997) - but any analysis of comparatives that delivers a suitable interpretation for differentials would work as well.

We generalize new dref introduction to deal with plural info states and with the simultaneous introduction of an arbitrary finite sequence of drefs $v_{m_{1}}, \ldots, v_{m_{n}}$ (where $v$ stands for $u$ or $\Delta$ and $m_{1}, \ldots, m_{n}$ are natural numbers) as shown below.

$$
\begin{aligned}
& I\left[u_{n}\right] J:=\forall i_{s} \in I\left(\exists j_{s} \in J\left(i\left[u_{n}\right] j\right)\right) \wedge \forall j_{s} \in J\left(\exists i_{s} \in I\left(i\left[u_{n}\right] j\right)\right) \text { and } \\
& I\left[\Delta_{n}\right] J:=\forall i_{s} \in I\left(\exists j_{s} \in J\left(i\left[\Delta_{n}\right] j\right)\right) \wedge \forall j_{s} \in J\left(\exists i_{s} \in I\left(i\left[\Delta_{n}\right] j\right)\right)
\end{aligned}
$$

Dynamic conjunction: $\mathbb{D} ; \mathbb{D}^{\prime}:=\lambda I_{s t} \cdot \lambda J_{s t} . \exists H_{s t}\left(\mathbb{D} I H \wedge \mathbb{D}^{\prime} H J\right)$

Multiple dref introduction: $\left[v_{m_{1}}, \ldots, v_{m_{n}}\right]:=\left[v_{m_{1}}\right] ; \ldots ;\left[v_{m_{n}}\right]$

We can now define the maximization operator max needed to capture the variable conditionality of comparative correlatives. As shown in (34) below, the result of updating an input state $I$ with a DRS $\max (\mathbb{D})$ is the maximal set $J$ that we can get when we update $I$ with the DRS $\mathbb{D}: J$ stores all the stacks / cases that satisfy $\mathbb{D}$.

$$
\max (\mathbb{D}):=\lambda I_{s t} \cdot \lambda J_{s t} . D I J \wedge \forall K_{s t}(D I K \rightarrow K \subseteq J)
$$

Finally, we define an operator over stacks that removes the first individual in a stack $i:^{11}$ the stack $i^{e-1}$ is the same as $i$ except that the first position of type $e$ has been dropped. $^{12}$ The operator is generalized to DRSs as shown in (35) below: a DRS $(\mathbb{D})^{e-1}$ updates an input state $I$ by updating each stack $i \in I$ as if the first object of type $e$ in that stack did not exist. The $(\ldots)^{e-1}$ operator enables us to solve the compositionality problem posed by comparative correlatives without than-phrases.

$$
\begin{aligned}
& (\mathbb{D})^{e-1}:=\lambda I_{s t} \cdot \lambda J_{s t} . \exists \mathbb{R}_{s((s t) t)} \neq \emptyset(I=\operatorname{Dom}(\mathbb{R}) \wedge J=\cup \operatorname{Ran}(\mathbb{R}) \wedge \\
& \left.\forall k_{s} \forall L_{s t}\left(\mathbb{R} k L \rightarrow\left\{\left((k)_{e}\right)_{0}\right\}=\left((L)_{e}\right)_{0} \wedge \mathbb{D}\left\{k^{e-1}\right\} L^{e-1}\right)\right)^{13}
\end{aligned}
$$

The dynamic notion of truth is defined as usual, i.e., as existential 'closure'.

$$
\text { Truth: a DRS } \mathbb{D}_{(s t)((s t) t)} \text { is true relative to an info state } I_{s t} \text { iff } \exists J_{s t}(D I J) \text {. }
$$

\subsection{Non-Conditional Comparative Correlatives}

Given the underlying type logic, we can define a Montague-style compositional interpretation procedure. This is largely determined by the types for the 'saturated' expressions, i.e., names and sentences, which we abbreviate as e and t. An extensional static framework identifies $\mathbf{e}$ with $e$ and $\mathbf{t}$ with $t$. The translation of the noun lawyer is of type et, i.e., et: lawyer $\rightsquigarrow \lambda x_{e} . l w_{e t}(x)$. The indefinite article $a$ is of type $($ et $)((\mathbf{e t}) \mathbf{t})$, i.e., $(e t)((e t) t): a \rightsquigarrow \lambda X_{e t} . \lambda X^{\prime}{ }_{e t} \cdot \exists x_{e}\left(X(x) \wedge X^{\prime}(x)\right)$.

\footnotetext{
${ }^{11}$ This operator can be generalized to remove the first position storing a time, a world, an eventuality etc. - or to remove the first $n$ positions storing individuals, times, worlds etc.

${ }^{12} i^{e-1}=i j \cdot\left(\operatorname{lng}\left((i)_{e}\right)=0 \rightarrow \operatorname{lng}\left((j)_{e}\right)=0\right) \wedge\left(\operatorname{lng}\left((i)_{e}\right) \neq 0 \rightarrow \operatorname{lng}\left((j)_{e}\right)=\operatorname{lng}\left((i)_{e}\right)-1 \wedge \forall n<\right.$ $\left.\operatorname{lng}\left((j)_{e}\right)\left(\left((j)_{e}\right)_{n}=\left((i)_{e}\right)_{n+1}\right)\right) \wedge(j)_{\gamma t}=(i)_{\gamma t}$.

${ }^{13} \operatorname{Dom}(\mathbb{R}):=\{k: \exists L(\mathbb{R} k L)\}, \operatorname{Ran}(\mathbb{R}):=\{L: \exists k(\mathbb{R} k L)\},\left((L)_{e}\right)_{0}:=\left\{\left((l)_{e}\right)_{0}: l \in L\right\}$ and $L^{e-1}:=$ $\left\{l^{e-1}: l \in L\right\}$.
} 
In the present dynamic system, we let $\mathbf{t}:=(s t)((s t) t)$, i.e., a sentence is interpreted as a DRS, and $\mathbf{e}:=s e$, i.e., a name is interpreted as a dref. The denotation of the noun lawyer is still of type et, as shown in (37) below. The indefinite article $a$ is still of type $($ et $)((\mathbf{e t}) \mathbf{t})$ : as shown in (38), it introduces the dref $u_{n}$ with which it is superscripted and predicates the restrictor and nuclear scope properties $P$ and $P^{\prime}$ of this dref. Pronouns are translated as the Montagovian lift of the dref they anaphorically retrieve (type (et)t), as shown in (39). Anaphoric definite articles receive the expected translation in (40) (type $($ et $)(($ et $) \mathbf{t}))$. We abbreviate the type of drefs for intervals as $\Gamma:=s(\gamma t)$ and translate the adjective tal $I$ as shown in (41) (type $\boldsymbol{\Gamma}(\mathbf{e t})) . P, P^{\prime}, \ldots$ are variables of type et over dynamic properties of individuals, $u, u^{\prime}, \ldots$ are variables of type $\mathbf{e}$ and $\Delta, \Delta^{\prime}, \ldots$ are variables of type $\Gamma$.

$$
\begin{aligned}
& \text { lawyer } \rightsquigarrow \lambda u_{\mathbf{e}} \cdot[l w\{u\}], \text { i.e., lawyer } \rightsquigarrow \lambda u_{\mathbf{e}} \cdot \lambda I_{s t} \cdot \lambda J_{s t} \cdot I=J \wedge l w\{u\} J \\
& a^{u_{n}} \rightsquigarrow \lambda P_{\text {et }} \cdot \lambda P_{\text {et }}^{\prime} \cdot\left[u_{n}\right] ; P\left(u_{n}\right) ; P^{\prime}\left(u_{n}\right) \\
& \text { he } e_{u_{n}} / \text { pro } o_{u_{n}} \rightsquigarrow \lambda P_{\text {et }} \cdot P\left(u_{n}\right) \\
& \text { the } e_{u_{n}} \rightsquigarrow \lambda P_{\text {et }} \cdot \lambda P_{\text {et }}^{\prime} \cdot P\left(u_{n}\right) ; P^{\prime}\left(u_{n}\right) \\
& \text { tall } \rightsquigarrow \lambda \Delta_{\Gamma} \cdot \lambda u_{\mathbf{e}} \cdot[\operatorname{tall}\{u, \Delta\}]
\end{aligned}
$$

I take Romanian comparative correlatives to have roughly the same syntactic structure as the one proposed in Beck (1997). More precisely, I take them to be IPadjunction structures ${ }^{14}$ in which the topic clause (the protasis) is an IP adjoined to the comment clause (the apodosis), which is also an IP - as shown in (42) below.

$$
\begin{aligned}
& {\left[I P\left[I P[\mathrm{Cu} \text { cît mai }]^{\Delta}\left[I^{\prime \prime} \text { e } \Delta \text {-înalt fratele }\right]\left[{ }_{C P}[\mathrm{dec} \hat{\mathrm{t} t}]^{\Delta^{\prime}} \text { sora e } \Delta^{\prime} \text {-înaltă }\right]\right]\right.} \\
& \left.\left[I P[\text { (tot) cu atît mai }]^{\Delta^{\prime \prime}}\left[{ }_{I} \text { e } \Delta^{\prime \prime} \text {-înalt tatăl }\right]\left[C P[\mathrm{dec} \hat{\mathrm{t}}]^{\Delta^{\prime \prime \prime}} \text { mama e } \Delta^{\prime \prime \prime} \text {-înaltă }\right]\right]\right]
\end{aligned}
$$

The wh-differential $c u$ cht and the differential anaphor $c u$ at $\hat{\imath} t$ are in the Spec-IP of their respective clauses - since they are in complementary distribution with the subjects. I assume that the syntax of comparatives involves two instances of quantifying-in per comparative (see Schwarzschild (2008) and references therein for more discussion), adding up to four in a comparative correlative. The superscripted variables $\Delta, \Delta^{\prime}, \Delta^{\prime \prime}$ and $\Delta^{\prime \prime \prime}$ indicate where quantifying-in - hence, $\lambda$-abstraction - occurs. Finally, I follow Beck (1997: 248 et seqq) and take the comparative morpheme mai (more) to form a constituent with the differentials.

The meanings for mai, $c u$ cht and $c u$ at $\hat{\imath} t$ in (43), (44) and (45) below are based on the syntax in (42) above. The proposed semantics for comparative correlatives, however, is compatible with other syntactic analyses (and frameworks). The wh-phrase decit and the copula $e$ are vacuous - they denote identity functions of the appropriate types: $(\boldsymbol{\Gamma} \mathbf{t})(\boldsymbol{\Gamma} \mathbf{t})$ for decit and $\mathbf{t t}$ (or $(\mathbf{e t})(\mathbf{e t}))$ for the copula. $P, P^{\prime}, \ldots$ are variables of type $\Gamma \mathbf{t}$ over dynamic properties of intervals and $\mathrm{R}$ is a variable of type $\boldsymbol{\Gamma}(\boldsymbol{\Gamma}(\boldsymbol{\Gamma} \mathbf{t}))$ over ternary dynamic relations between intervals.

$$
\operatorname{mai} \rightsquigarrow \lambda \Delta_{\Gamma} \cdot \lambda \Delta^{\prime} \Gamma \cdot \lambda \Delta^{\prime \prime} \Gamma \cdot\left[\Delta^{\prime \prime} \neq \emptyset, \Delta^{\prime \prime}=\Delta \backslash \Delta^{\prime}\right]^{15}
$$

\footnotetext{
${ }^{14}$ Not $\mathrm{CP}$-adjunction structures, because they can occur in attitude reports embedded under an overt complementizer, e.g., embedded under Irina crede că ... (Irina believes that ...).

${ }^{15} \Delta^{\prime \prime} \neq \emptyset:=\lambda I_{s t} . I \neq \emptyset \wedge \forall i_{s} \in I\left(\Delta^{\prime \prime} i \neq \emptyset\right)$ and $\Delta^{\prime \prime}=\Delta \backslash \Delta^{\prime}:=\lambda I_{s t} . I \neq \emptyset \wedge \forall i_{s} \in I\left(\Delta^{\prime \prime} i=\Delta i \backslash \Delta^{\prime} i\right)$.
} 


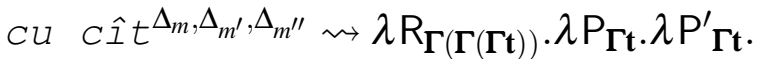

$$
\begin{aligned}
& \max \left(\left[\Delta_{m}\right] ; \mathrm{P}\left(\Delta_{m}\right) ;\left[\Delta_{m^{\prime}}\right] ; \mathrm{P}^{\prime}\left(\Delta_{m^{\prime}}\right) ;\left[\Delta_{m^{\prime \prime}}\right] ; \mathrm{R}\left(\Delta_{m}\right)\left(\Delta_{m^{\prime}}\right)\left(\Delta_{m^{\prime \prime}}\right)\right)
\end{aligned}
$$

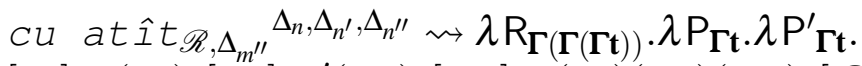

$$
\begin{aligned}
& {\left[\Delta_{n}\right] ; \mathrm{P}\left(\Delta_{n}\right) ;\left[\Delta_{n^{\prime}}\right] ; \mathrm{P}^{\prime}\left(\Delta_{n^{\prime}}\right) ;\left[\Delta_{n^{\prime \prime}}\right] ; \mathrm{R}\left(\Delta_{n}\right)\left(\Delta_{n^{\prime}}\right)\left(\Delta_{n^{\prime \prime}}\right) ;\left[\mathscr{R}\left(\Delta_{m^{\prime \prime}}, \Delta_{n^{\prime \prime}}\right)\right]}
\end{aligned}
$$

The max operator in the meaning of $C u \quad C \hat{\imath} t$ is contributed by its wh-morphology. In contrast, $\mathrm{cu} 2 \mathrm{~cm}$ or the null differential - translated in (46) and (47) below do not have such an operator. The null differential, which I assume occurs in 'bare' comparatives like Gabby is taller than Linus, is, basically, just existential closure over the differential argument of the comparative morpheme mai (more).

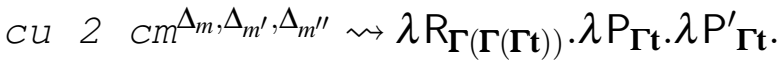

$$
\begin{aligned}
& {\left[\Delta_{m}\right] ; \mathrm{P}\left(\Delta_{m}\right) ;\left[\Delta_{m^{\prime}}\right] ; \mathrm{P}^{\prime}\left(\Delta_{m^{\prime}}\right) ;\left[\Delta_{m^{\prime \prime}}\right] ; \mathrm{R}\left(\Delta_{m}\right)\left(\Delta_{m^{\prime}}\right)\left(\Delta_{m^{\prime \prime}}\right) ;\left[\mathbf{2} \mathbf{c m}\left\{\Delta_{m^{\prime \prime}}\right\}\right]^{16}}
\end{aligned}
$$

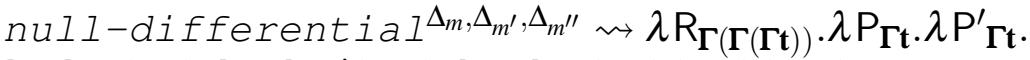

$$
\begin{aligned}
& {\left[\Delta_{m}\right] ; \mathrm{P}\left(\Delta_{m}\right) ;\left[\Delta_{m^{\prime}}\right] ; \mathrm{P}^{\prime}\left(\Delta_{m^{\prime}}\right) ;\left[\Delta_{m^{\prime \prime}}\right] ; \mathrm{R}\left(\Delta_{m}\right)\left(\Delta_{m^{\prime}}\right)\left(\Delta_{m^{\prime \prime}}\right)}
\end{aligned}
$$

We conjoin the matrix and than clauses of a comparative - in that order - because we have anaphora from the latter to the former, e.g., $A^{u_{0}}$ man was $2 \mathrm{~cm}$ taller than his $s_{u_{0}}$ son, but not vice versa, e.g., \#His $u_{u_{0}}$ son was $2 \mathrm{~cm}$ taller than $a^{u_{0}}$ man.

The meaning of the anaphoric differential at $\hat{\imath} t$ in (45) above contains a relational dref $\mathscr{R}$, whose value is contextually supplied. Its default value is the Cartesian product over the domain of intervals, but the particle tot or various pragmatic factors can require it to be the identity relation over intervals (see the discussion in section 2 above). For simplicity, however, we will ignore this relational dref and work with the two translations in (48) and (49) below: (48) corresponds to the 'Cartesian product $\mathscr{R}$ ' case, which reduces to no anaphora to differentials whatsoever; (49) corresponds to the 'identity $\mathscr{R}$ ' case, which reduces to direct anaphora to a previously introduced differential interval.

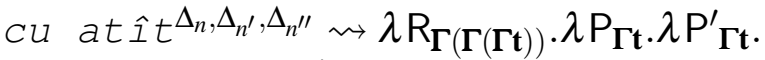

$$
\begin{aligned}
& {\left[\Delta_{n}\right] ; \mathrm{P}\left(\Delta_{n}\right) ;\left[\Delta_{n^{\prime}}\right] ; \mathrm{P}^{\prime}\left(\Delta_{n^{\prime}}\right) ;\left[\Delta_{n^{\prime \prime}}\right] ; \mathrm{R}\left(\Delta_{n}\right)\left(\Delta_{n^{\prime}}\right)\left(\Delta_{n^{\prime \prime}}\right)} \\
& \text { (tot) cu atît } t_{\Delta_{m^{\prime \prime}}} \Delta_{n}, \Delta_{n^{\prime}} \rightsquigarrow \lambda \mathrm{R}_{\Gamma(\Gamma(\Gamma \mathbf{t}))} \cdot \lambda \mathrm{P}_{\Gamma \mathbf{t}} \cdot \lambda \mathrm{P}^{\prime} \Gamma \mathbf{t} \text {. } \\
& {\left[\Delta_{n}\right] ; \mathrm{P}\left(\Delta_{n}\right) ;\left[\Delta_{n^{\prime}}\right] ; \mathrm{P}^{\prime}\left(\Delta_{n^{\prime}}\right) ; \mathrm{R}\left(\Delta_{n}\right)\left(\Delta_{n^{\prime}}\right)\left(\Delta_{m^{\prime \prime}}\right)}
\end{aligned}
$$

The comparative correlative in (1) above is indexed as shown in (50) below and it is compositionally translated as shown in (51). Given the definition of dynamic truth in (36), the translation derives the intuitively correct truth conditions in (2) above. The update proceeds as shown in (52): the anaphoric definites retrieve the contextually specified values for the drefs $u_{0}, u_{1}, u_{2}$ and $u_{3}$. The differential $c u$ $c \hat{I} t$ in the topic clause / protasis updates the context by introducing an interval dref $\Delta_{2}$ that stores the difference between the brother's height $\Delta_{0}$ and the sister's height $\Delta_{1}$. The comment clause / apodosis receives a parallel interpretation, except

\footnotetext{
${ }^{16} \mathbf{2} \mathbf{c m}\left\{\Delta_{m^{\prime \prime}}\right\}:=\lambda I_{s t} . I \neq \emptyset \wedge \forall i_{s} \in I\left(\mathbf{2 m m}\left(\Delta_{m^{\prime \prime}} i\right)\right)$ and $\mathbf{2} \mathbf{c m}$ is the set of $2 \mathrm{~cm}$ intervals (type $\left.(\gamma t) t\right)$.
} 
that $c u$ atit anaphorically retrieves the differential interval $\Delta_{2}$ and equates it with the difference between the father's height $\Delta_{3}$ and the mother's height $\Delta_{4} \cdot{ }^{17}$

(50) $\mathrm{Cu} \mathrm{cît}{ }^{\Delta_{0}, \Delta_{1}, \Delta_{2}}$ e mai înalt fratele $u_{0}$ decît sora $u_{u_{1}}$, (tot) cu atît ${ }_{\Delta_{2}} \Delta_{3}, \Delta_{4}$ e mai înalt tatăl $\mathrm{u}_{u_{2}}$ decît mama $u_{u_{3}}$.

$$
\begin{aligned}
& \max \left(\left[\Delta_{0} \mid \text { tall }\left\{u_{0}, \Delta_{0}\right\}\right] ;\left[\Delta_{1} \mid \text { tall }\left\{u_{1}, \Delta_{1}\right\}\right] ;\left[\Delta_{2} \mid \Delta_{2} \neq \emptyset, \Delta_{2}=\Delta_{0} \backslash \Delta_{1}\right]\right) ; \\
& {\left[\Delta_{3} \mid \text { tall }\left\{u_{2}, \Delta_{3}\right\}\right] ;\left[\Delta_{4} \mid \text { tall }\left\{u_{3}, \Delta_{4}\right\}\right] ;\left[\Delta_{2} \neq \emptyset, \Delta_{2}=\Delta_{3} \backslash \Delta_{4}\right]}
\end{aligned}
$$

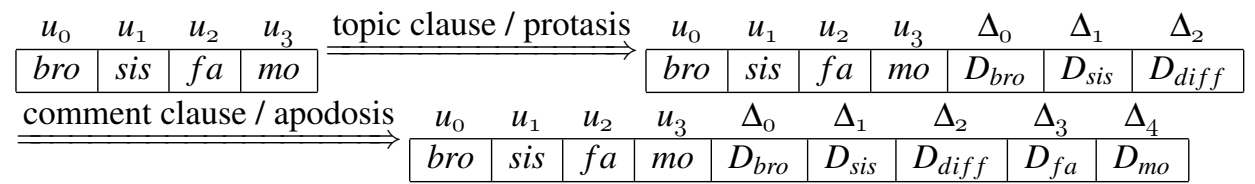

\subsection{Conditional Comparative Correlatives}

The comparative correlative with overt than-phrases in (5) above is indexed as shown in (55) below and it is compositionally translated as shown in (56) (the translation of the infelicitous variant with the particle tot present can be obtained if we use 49 above instead of 48). Once again, the translation derives the intuitively correct truth conditions. The only difference between the truth conditions derived based on (56) and the ones in (8) above (besides the final conjunct $D=D^{\prime}$ in 8 , which is due to the particle tot) is that the former have an additional existential requirement that there is at least one case satisfying the protasis, i.e., that there are at least two natural numbers such that one of them is greater than the other. This additional requirement is, in fact, part of the meaning of comparative correlatives (see Beck 1997: 253) and of correlative and quantificational structures in general, which are felicitous only if their domains are non-empty.

$$
\begin{aligned}
& \text { the } e^{u_{n}} \rightsquigarrow \lambda P_{\text {et }} \cdot \lambda P^{\prime} \text { et. unique }{ }^{u_{n}}\left(P\left(u_{n}\right)\right) ; P^{\prime}\left(u_{n}\right)^{18} \\
& \text { altuI } I_{u_{m}}{ }_{n} / \text { an }^{u_{n}} \text { other }_{u_{m}} \text { nat. number } \rightsquigarrow \lambda P_{\text {et }}\left[u_{n} \mid u_{n} \neq u_{m}, u_{n} \in \mathbb{N}\right] ; P\left(u_{n}\right)^{19} \\
& \mathrm{Cu} \mathrm{cît}{ }^{\Delta_{0}, \Delta_{1}, \Delta_{2}} \text { e un }^{u_{0}} \text { număr natural mai mare decît altul } u_{u_{0}} u_{1} \text {, } \\
& \text { cu atît }{ }^{\Delta_{3}, \Delta_{4}, \Delta_{5}} \text { e pătratul }{ }^{u_{2}} \text { lui }_{u_{0}} \text { mai mare decît pătratul }{ }^{u_{3}} \text { celuilalt }_{u_{1}} \text {. } \\
& \max \left(\left[\Delta_{0}, u_{0} \mid u_{0} \in \mathbb{N} \text {, great }\left\{u_{0}, \Delta_{0}\right\}\right] ;\left[\Delta_{1}, u_{1} \mid u_{1} \neq u_{0}, u_{1} \in \mathbb{N} \text {, great }\left\{u_{1}, \Delta_{1}\right\}\right] ;\right. \\
& \left.\left[\Delta_{2} \mid \Delta_{2} \neq \emptyset, \Delta_{2}=\Delta_{0} \backslash \Delta_{1}\right]\right) ; \text { unique }^{u_{2}}\left(\left[\text { square }\left\{u_{2}, u_{0}\right\}\right]\right) ;\left[\Delta_{3} \mid \text { great }\left\{u_{2}, \Delta_{3}\right\}\right] \text {; } \\
& \text { unique }^{u_{3}}\left(\left[\text { square }\left\{u_{3}, u_{1}\right\}\right]\right) ;\left[\Delta_{4} \mid \text { great }\left\{u_{3}, \Delta_{4}\right\}\right] ;\left[\Delta_{5} \mid \Delta_{5} \neq \emptyset, \Delta_{5}=\Delta_{3} \backslash \Delta_{4}\right]
\end{aligned}
$$

\footnotetext{
${ }^{17}$ The equative correlative in (3) is analyzed in terms of anaphora to the interval obtained by subtracting the (contextual) standard of beauty from Irina's maximal degree of beauty. This interval is correlated with the one obtained by subtracting the contextual standard of smartness from Irina's maximal degree of smartness. Equative correlatives that do not involve reference to contextual standards, e.g., the correlative mentioned in footnote $\mathbf{1}$ above, correlate the intervals between the 0 -points on the relevant scales and the maximal degrees under consideration.

${ }^{18}$ unique $^{u_{n}}(\mathbb{D}):=\lambda I_{s t} \cdot \lambda J_{s t} . \exists \mathbb{R}_{s((s t) t)} \neq \emptyset\left(I=\operatorname{Dom}(\mathbb{R}) \wedge J=\cup \operatorname{Ran}(\mathbb{R}) \wedge \forall k_{s} \forall L_{s t}(\mathbb{R} k L \rightarrow\right.$ $\left.\left.\left(\left[u_{n}\right] ; \mathbb{D}\right)\{k\} L \wedge\left|u_{n} L\right|=1 \wedge \forall L_{s t}^{\prime}\left(\left(\left[u_{n}\right] ; \mathbb{D}\right)\{k\} L^{\prime} \rightarrow u_{n} L^{\prime}=u_{n} L\right)\right)\right)$, where $u_{n} L:=\left\{u_{n} l: l \in L\right\}$.

${ }^{19} u_{n} \neq u_{m}:=\lambda I_{s t} . I \neq \emptyset \wedge \forall i_{s} \in I\left(u_{n} i \neq u_{m} i\right)$ and $u_{n} \in \mathbb{N}:=\lambda I_{s t} . I \neq \emptyset \wedge \forall i_{s} \in I\left(u_{n} i \in \mathbb{N}\right)$.
} 


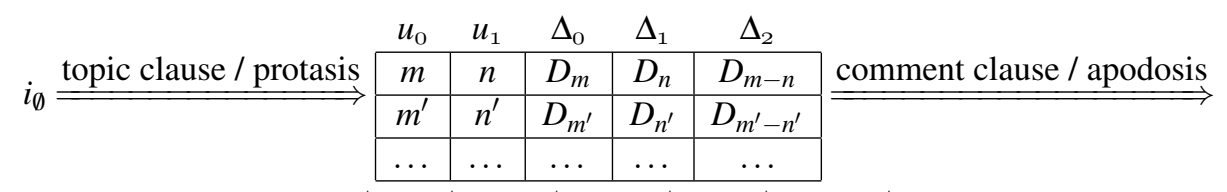

\begin{tabular}{|c|c|c|c|c|c|c|c|c|c|}
\hline$u_{\mathrm{o}}$ & $u_{1}$ & $u_{2}$ & $u_{3}$ & $\Delta_{0}$ & $\Delta_{1}$ & $\Delta_{2}$ & $\Delta_{3}$ & $\Delta_{4}$ & $\Delta_{5}$ \\
\hline$m$ & $n$ & $m^{2}$ & $n^{2}$ & $D_{m}$ & $D_{n}$ & $D_{m-n}$ & $D_{m^{2}}$ & $D_{n^{2}}$ & $D_{m^{2}-n^{2}}$ \\
\hline$m^{\prime}$ & $n^{\prime}$ & $m^{\prime 2}$ & $n^{\prime 2}$ & $D_{m^{\prime}}$ & $D_{n^{\prime}}$ & $D_{m^{\prime}-n^{\prime}}$ & $D_{m^{\prime 2}}$ & $D_{n^{\prime 2}}$ & $D_{m^{\prime 2}-n^{\prime 2}}$ \\
\hline$\ldots$ & $\ldots$ & $\ldots$ & $\ldots$ & $\ldots$ & $\ldots$ & $\ldots$ & $\ldots$ & $\ldots$ & $\cdots$ \\
\hline
\end{tabular}

We finally turn to the comparative correlative without overt than-phrases in (4) above. Compositionally deriving the meaning of such correlatives is problematic because, just as the other comparative correlatives we considered, they involve a comparison in both the protasis and the apodosis, but the second term of comparison is missing in both cases - and, as Beck (1997) notes, it is intuitively provided by reusing the first term of comparison, i.e., by using the two overt clauses twice.

Formally, the problem with this 'double use' idea is that both static and dynamic approaches find it difficult to introduce the variable contributed by the protasis indefinite a lawyer twice, make the two occurrences of the variable semantically independent and anaphorically retrieve them as two independent variables with the same pronoun in the apodosis, which, to this end, is also used twice.

This is ultimately the reason for the non-compositionality of the account in Beck (1997), where we need to postulate the existence of pairs of individual / temporal / world variables (as the case may be; cf. p. 248:42 and p. 252:49a,b) in the meaning of the correlative particles, then we need to coindex these variables with a covert adverb of quantification that takes scope over the entire correlative structure and, finally, we need these variables to satisfy two predicates obtained by covert $\lambda$-abstraction over the indefinite in the protasis of (4) and the pronoun in the apodosis of (4). That is, most of the work in deriving the correct truth conditions is done not by the meanings of the lexical items and the syntax-based way they are put together, but by postulating covert pairs of variables and a variety of covert operators inserted in particular structural positions that are suitably coindexed with both the covert variables and the overtly present indefinites and pronouns.

I take the basic intuition behind the 'double use' proposal to be that the protasis clause is used not once, but twice to update the context, so the context changes brought about by this clause are recorded twice (the same goes for the apodosis clause) - and I will use the $(\ldots)^{e-1}$ operator to formalize this intuition. The 'double update' analysis is just this: the first update is executed as usual, while the second update with the same clause is executed in the scope of a $(\ldots)^{e-1}$ operator. The operator temporarily removes the first $e$-position (contributed by the first update) and reattaches it after the second update is executed. The idea is that we treat the second execution of the update as if it was the first one, i.e., we interpret the subordinate than-clause as if it temporarily was the matrix clause. This is analogous to the way we manipulate world variables when we interpret clauses embedded under modal operators: the world variables contributed by the modal operators are treated as if they were the actual world and, given this temporary assumption, we interpret 
the embedded clauses as if they were matrix clauses. ${ }^{20}$

The two $(\ldots)^{e-1}$ operators (one in the protasis, the other in the apodosis) are contributed by the two correlated differentials. Their translations, related in a reflexivization-like way to the translations in (44) and (48) above, are provided in (58) and (59) below. The proposal that, cross-linguistically, the presence vs. absence of than-phrases in comparative correlatives is licensed by the lexical properties of the correlated differentials is supported by the fact that Russian has two such pairs of differentials, naskol'ko...nastol'ko... and čem...tem..., the first of which is used for comparative correlatives with than-phrases, while the second is used for comparative correlatives without than-phrases. ${ }^{21}$

$$
\begin{aligned}
& \text { cu } \quad c \hat{\imath} t^{\Delta_{m}, \Delta_{m^{\prime}}, \Delta_{m^{\prime \prime}}, e-1} \rightsquigarrow \lambda \mathrm{R}_{\Gamma(\boldsymbol{\Gamma}(\boldsymbol{\Gamma} \mathbf{t}))} \cdot \lambda \mathrm{P}_{\Gamma \mathbf{t}} . \\
& \max \left(\left[\Delta_{m}\right] ; \mathrm{P}\left(\Delta_{m}\right) ;\left[\Delta_{m^{\prime}}\right] ;\left(\mathrm{P}\left(\Delta_{m^{\prime}}\right)\right)^{e-1} ;\left[\Delta_{m^{\prime \prime}}\right] ; \mathrm{R}\left(\Delta_{m}\right)\left(\Delta_{m^{\prime}}\right)\left(\Delta_{m^{\prime \prime}}\right)\right) \\
& \text { cu at } \hat{\imath} t^{\Delta_{n}, \Delta_{n^{\prime}}, \Delta_{n^{\prime \prime}}, e-1} \rightsquigarrow \lambda \mathrm{R}_{\boldsymbol{\Gamma}}(\boldsymbol{\Gamma}(\boldsymbol{\Gamma} \mathbf{t})) \cdot \lambda \mathrm{P}_{\Gamma \mathbf{t}} . \\
& {\left[\Delta_{n}\right] ; \mathrm{P}\left(\Delta_{n}\right) ;\left[\Delta_{n^{\prime}}\right] ;\left(\mathrm{P}\left(\Delta_{n^{\prime}}\right)\right)^{e-1} ;\left[\Delta_{n^{\prime \prime}}\right] ; \mathrm{R}\left(\Delta_{n}\right)\left(\Delta_{n^{\prime}}\right)\left(\Delta_{n^{\prime \prime}}\right)}
\end{aligned}
$$

The comparative correlative in (4) is indexed as shown in (60) below and it is compositionally translated as shown in (61). The translation derives the intuitively correct truth conditions in (7) above - with the addition of the existential requirement that there are at least two lawyers with different degrees of aggressiveness.

$\mathrm{Cu}$ cit $^{\Delta_{0}, \Delta_{1}, \Delta_{2}, e-1}$ e un $^{u_{0}}$ avocat mai agresiv, cu atît ${ }^{\Delta_{3}, \Delta_{4}, \Delta_{5}, e-1}$ e pro ${ }_{u_{0}}$ mai eficient.

$\max \left(\left[\Delta_{0}, u_{0} \mid l w\left\{u_{0}\right\}, \operatorname{aggr}\left\{u_{0}, \Delta_{0}\right\}\right] ;\left[\Delta_{1}\right] ;\left(\left[u_{0} \mid \operatorname{lw}\left\{u_{0}\right\}, \operatorname{aggr}\left\{u_{0}, \Delta_{1}\right\}\right]\right)^{e-1} ;\right.$ $\left.\left[\Delta_{2} \mid \Delta_{2} \neq \emptyset, \Delta_{2}=\Delta_{0} \backslash \Delta_{1}\right]\right)$;

$\left[\Delta_{3} \mid \operatorname{eff}\left\{u_{0}, \Delta_{3}\right\}\right] ;\left[\Delta_{4}\right] ;\left(\left[\operatorname{eff}\left\{u_{0}, \Delta_{4}\right\}\right]\right)^{e-1} ;\left[\Delta_{5} \mid \Delta_{5} \neq \emptyset, \Delta_{5}=\Delta_{3} \backslash \Delta_{4}\right]$

$\left.i_{\emptyset} \stackrel{\text { topic clause / protasis }}{\longrightarrow} \begin{array}{c|c|c|c|c|c}u_{0} & u_{1} & \Delta_{0} & \Delta_{1} & \Delta_{2} \\ \hline x & y & D_{x} & D_{y} & D_{x-y} \\ \hline x^{\prime} & y^{\prime} & D_{x^{\prime}} & D_{y^{\prime}} & D_{x^{\prime}-y^{\prime}} \\ \hline \ldots & \ldots & \ldots & \ldots & \ldots \\ \hline\end{array}\right]$ comment clause / apodosis

\footnotetext{
${ }^{20}$ Another way to formalize the 'double update' analysis is to follow Bittner (2001) and model contexts not as single stacks (or sets thereof), but as pairs of stacks, one storing the foregrounded / topical drefs, the other one storing the backgrounded drefs. The 'double use' of a clause in comparative correlatives like (4) is, once again, double update: we update the topical stack the first time around and, then, we reuse the same protasis clause to update the background stack. We thus obtain two independent drefs (a foregrounded and a backgrounded one) that can be anaphorically retrieved by the apodosis pronoun in a parallel 'double update' way.

${ }^{21}$ The Russian counterpart of (1) is: Naskol'ko brat vyše čem sestra, nastol'ko otec vyše čem mat' (in-how-much brother.Nom taller than sister.Nom, insomuch father.Nom taller than mother.Nom). Expressing the two than-phrases by means of the Genitives sestry (sister.Gen) and materi (mother.Gen) is also possible. The Russian counterpart of (4) is: $\check{C}$ em advokat agressivnee, tem on éffektivnee. (than lawyer.Nom more-aggressive that.Instr he more-effective). The data, however, is more complicated, since there are two Russian counterparts of (5), one of them with a than-phrase in the protasis, i.e., Čem bol'še odno natural'noe čislo čem drugoe, tem bol'še (i) ego kvadrat. (than bigger one natural number.Nom than other.Nom, that.Instr bigger (and/EMPH) its square.Nom) (expressing the than-phrase by means of the Genitive drugogo (other.Gen) is also possible) and the other one without any than-phrase, i.e., Čem bol'še natural'noe čislo, tem bol'še (i) ego kvadrat. (than bigger natural number.Nom, that.Instr bigger (and/EMPH) its square.Nom).
} 


\begin{tabular}{|c|c|c|c|c|c|c|c|}
\multicolumn{1}{c}{$u_{0}$} & $u_{1}$ & \multicolumn{1}{c}{$\Delta_{0}$} & $\Delta_{1}$ & $\Delta_{2}$ & $\Delta_{3}$ & $\Delta_{4}$ & $\Delta_{5}$ \\
\hline$x$ & $y$ & $D_{x}$ & $D_{y}$ & $D_{x-y}$ & $D^{\prime}{ }_{x}$ & $D^{\prime}{ }_{y}$ & $D^{\prime}{ }_{x-y}$ \\
\hline$x^{\prime}$ & $y^{\prime}$ & $D_{x^{\prime}}$ & $D_{y^{\prime}}$ & $D_{x^{\prime}-y^{\prime}}$ & $D^{\prime}{ }_{x^{\prime}}$ & $D^{\prime}{ }_{y^{\prime}}$ & $D^{\prime}{ }_{x^{\prime}-y^{\prime}}$ \\
\hline$\ldots$ & $\ldots$ & $\ldots$ & $\ldots$ & $\ldots$ & $\ldots$ & $\ldots$ & $\ldots$ \\
\hline
\end{tabular}

\section{References}

Beck, Sigrid: 1997, 'On the Semantics of Comparative Conditionals', Linguistics and Philosophy 20, 229-271.

van den Berg, Martin: 1996, Some Aspects of the Internal Structure of Discourse, Doctoral Dissertation, University of Amsterdam.

Bittner, Maria: 2001, 'Topical Referents for Individuals and Possibilities', in R. Hastings, B. Jackson, and Z. Zvolenszky (eds.), Proceedings of SALT XI, 36-55. CLC Publications, Cornell, Ithaca.

Brasoveanu, Adrian: 2007, Structured Nominal and Modal Reference, Doctoral Dissertation, Rutgers University.

Brasoveanu, Adrian: 2008, 'Uniqueness Effects in Correlatives', in A. Grønn (ed.), Proceedings of Sinn und Bedeutung 12, 47-65. ILOS, Oslo.

Dayal, Veneeta: 1996, Locality in Wh Quantification. Kluwer, Dordrecht.

den Dikken, Marcel: 2005, 'Comparative Correlatives Comparatively', Linguistic Inquiry 36, 497-532.

Jespersen, Otto: 1965, The Philosophy of Grammar. Norton \& Co., New York [originally 1924, London: Allen \& Unwin].

Karttunen, Lauri: 1976, 'Discourse Referents', in J. McCawley (ed.), Syntax and Semantics 7, 363-385. Academic Press, New York.

Lewis, David: 1975, 'Adverbs of Quantification', in E. Keenan (ed.), Formal Semantics of Natural Language, 3-15. Cambridge Univ. Press, Cambridge.

McCawley, James: 1988, 'The Comparative Conditional Construction in English, German and Chinese', in Proceedings of BLS 14, 176-187.

Muskens, Reinhard: 1996, 'Combining Montague Semantics and Discourse Representation', Linguistics and Philosophy 19, 143-186.

Nouwen, Rick: 2003, Plural Pronominal Anaphora in Context, Doctoral Dissertation, University of Utrecht.

Partee, Barbara: 1973, 'Some Structural Analogies between Tenses and Pronouns in English', Journal of Philosophy 70, 601-609.

Partee, Barbara: 1984, 'Nominal and Temporal Anaphora', Linguistics and Philosophy 7, 243-286.

Roberts, Craige: 1989, 'Modal Subordination and Pronominal Anaphora in Discourse', Linguistics and Philosophy 12, 683-721.

Schwarzschild, Roger: 2008, 'The Semantics of Comparatives and Other Degree Constructions', Language and Linguistics Compass 2, 308-331.

Stone, Matthew: 1999, 'Reference to Possible Worlds', RuCCS Report 49, Rutgers University, New Brunswick, NJ. 